ORIGINAL ARTICLES

\title{
Obstetric performance in elderly Nigerian women: A comparative study
}

\author{
Ezechi OC' ${ }^{\text {, Kalu BKE }}{ }^{2}$, Ndububa ${ }^{2}$, Loto OM ${ }^{3}$, Ezeobi PM' ${ }^{1}$, Nwokoro CA. ${ }^{2}$ \\ 1. Nigerian Institute of Medical Research, Yaba Lagos. Nigeria \\ 2. Havana Specialist Hospital, Lagos Nigeria \\ 3. Obafemi Awolowo University, Ile Ife, Nigeria
}

\begin{abstract}
Aims: To study the obstetric outcome in Nigerian women aged 35 years and above while comparing them with younger women matched for parity, socioeconomic class and body mass index.

Method: A cohort of 132 pregnant women aged 35 years and above with another 269 pregnant women aged 20-25 years matched for parity, socioeconomic class and body mass index seen at the obstetric unit of a multidisciplinary proprietary hospital in Lagos Nigeria.

Results: There were statistically significant difference between the two group in incidence of chronic hypertension $(P=0.02)$, gestational diabetes $(P=0.05)$, symptomatic fibroid $(P=0.01)$, frequent hospitalisation $(P=$ .007), caesarean section $(P=0.005)$, operative vaginal delivery $(P=0.042)$, Induction of labour $(P=$ $0.024)$ premature delivery $(P=.001)$, low birth weight $(P=0.021)$ and congenital abnormality but not in Preeclampsia, malpresentation, obstetric haemorrhage, wound infection and multiple pregnancy .
\end{abstract}

Conclusion: This study demonstrated that women at 35 years and above are high-risk group and should be closely supervised during pregnancy.

Keywords: Elderly, Nigerians, obstetric performance

\section{Introduction}

Traditionally, pregnancies in women of advanced age have been regarded as high risk ${ }^{1-7}$ They tend to acquire more chronic illness such as diabetes mellitus and hypertension, which are risk factors for adverse obstetric outcome. ${ }^{3,5,6-11}$ In addition, the incidence of fetal congenital abnormalities, spontaneous abortion, perinatal morbidity and mortality and other obstetric complications are increased. ${ }^{1,12-14}$

Previous studies especially in our environment have yielded conflicting results of the pregnancy outcome in women aged 35 years and older. The apparent conflicting reports are partly due to the fact that most of the studies were either retrospective or not case controlled..$^{3,5,6,910,15}$

In this study we prospectively studied pregnancy outcome in women aged 35 years and above in comparism to younger women aged $20-25$ years, while matching for parity, socioeconomic class and body mass index, since these factors are independent variables that could affect pregnancy outcome in these women. $5,6,7,10$

\section{Methods}

The study was conducted at the Havana Specialist Hospital, a multidisciplinary proprietary hospital located in the economic capital of Nigeria- Lagos. The hospital provides both specialized obstetrics and paediatric services.

From July $1^{\text {st }} 2000$ to December $31^{\text {st }} 2006$, all pregnant women aged 35 years and above seen during the period were recruited for the study. Two consecutive pregnant women aged between 20 and 25 years of same social class, parity and body mass index group following each woman aged 35 years and above were recruited 
as controls. Both groups were followed up till 6 weeks post delivery. All antenatal, labour, postnatal and neonatal events were collected and fed into an IBM compatible computer using SPSS version 10.0 for windows. For purposes of this study, parity was categorized into four groups (P0, P1 \& P2, P3 \& P4, 3 P5); Social class into three groups (classes I \& II, III, IV $\& \mathrm{~V}$ ) and body mass index into three groups (less than $20,20-25$ and $>25.0$. Social class classification was by Olusanya et $\mathrm{al}^{16 .}$ Comparisons were made between two groups in terms of antenatal, labour and delivery outcomes using Chi squared, student $t$ test and Fischer exact test as appropriate. The significant outcomes at univariate model were subjected to multiple logistic regressions while controlling for effect of parity, social class and body mass index. A P value of $<0.05$ was considered significant.

\section{Results}

During the study period 135 women aged 35 years and above and 270 women aged 20-25 years of matching parity, social class and body mass index meeting the inclusion criteria were seen and recruited for the study. Three women aged 35 years and above and one among the control group did not complete their antenatal and delivery in the hospital and were thus excluded from the since they had incomplete data.

There socio - demographic characteristics are shown in Table 1. Comparison using student t test showed that there were no significant difference between the two groups in parity, socioeconomic class and body mass index.

Maternal complications among these women are shown in Table 2. The medical disorders observed in these women were hypertensive disorders, diabetes mellitus and anaemia. While there was a statistically significant difference between the case group and the controls for hypertensive disorders $(\mathrm{p}=0.01)$, further analysis showed that it was only for chronic hypertension $(\mathrm{p}=$ 0.02 ), but not for preclampsia ( $\mathrm{P}=0.16$ ). There was also statistically significant difference between the two groups for the prevalence of gestational diabetes $(\mathrm{P}=$ $0.5)$. Though less number of women (5) among the study group was anaemic compare to ten in control group, the difference was not statistically significant. Other maternal complications that were statistically significantly different between the two groups were red degeneration of uterine fibroid $(p=0.01)$ and frequent antenatal admission. There were no statistically significant difference between the two groups in cases of malpresentation, obstetric haemorrhage, wound infection and multiple pregnancies.

Table 3 shows labour outcome between the two groups. The study group had a significant higher caesarean section rate than the control group and the operative vaginal delivery rate was also higher for the former $(P=0.001)$.

The gestational age at delivery among the elderly women of $36.5 \pm 1$.1 weeks was significantly lower than that of the younger women of $39.2 \pm 1.8$ weeks $(\mathrm{p}=0.000)$.

The newborns in the study group have smaller birth weight than those in the control group, but this is not statistically significant; however the incidence of low birth weight is significantly higher in the study group (Table 4). Also there were statistically significant difference between the control and the study groups in number of babies with congenital malformation and neonatal admission, but not in stillbirth and neonatal death rates. The types of congenital anomaly noted in the two groups are shown in Table 5. No maternal death occurred in these two groups.

\section{Discussion}

Pregnancies in women of advanced maternal age are considered to be high risk. ${ }^{3,4,5,7,10,13,17}$ Perinatal morbidity and mortality are also said to be increased. ${ }^{1,5,13,17}$

This study aimed at comparing the pregnancy outcome of elderly women to those of younger women aged 2025 years matched for parity, socioeconomic class and body mass index. Age group 20-25 years was used as control, because it has been shown by various studies

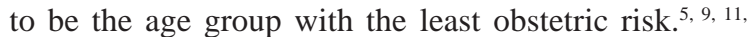
${ }^{19,20}$ We also matched for parity and body mass index because pregnancy in older women are associated with many confounding factors and should be controlled for, to remove the effect of these confounders. ${ }^{5,10,22}$

Table I. Sociodemographic characteristics of the women.

\begin{tabular}{|c|c|c|c|}
\hline Characteristics & Study group $\mathrm{n}=132$ & Control group $\mathrm{n}=269$ & P value \\
Mean parity & $2.3 \pm 2.1$ & $2.2 \pm 1.9$ & 0.16 \\
Mean social class & $1.9 \pm 1.2$ & $2.1 \pm 1.3$ & 0.33 \\
Mean BMI* & $23.0 \pm 3.7$ & $23.0 \pm 3.6$ & 0.30 \\
\hline
\end{tabular}

*Body mass index 
Table 2. Maternal complication recorded among the women.

\begin{tabular}{|l|c|c|c|c|}
\hline Characteristics & $\begin{array}{c}\text { Study group } \\
\mathrm{N}=132(\%)\end{array}$ & $\begin{array}{c}\text { Control group } \\
\mathrm{N}=269(\%)\end{array}$ & Chi square & P value \\
Hypertensive disorders & $22(16.7)$ & $17(6.1)$ & 7.37 & 0.007 \\
Chronic Hypertension & $9(6.8)$ & $2(0.8)$ & 5.09 & 0.02 \\
PIH* & $13(9.8)$ & $14(5.3)$ & 1.95 & 0.16 \\
Symptomatic fibroid & $15(11.4)$ & $8(3.0)$ & 5.67 & 0.009 \\
Gestational diabetes & $5(3.8)$ & $4(0.8)$ & 5.62 & 0.02 \\
Preexisting diabetes & $1(0.8)$ & $0(0.0)$ & 1.0 & 0.5 \\
Anaemia & $5(3.8)$ & $20(7.6)$ & 1.7 & 0.18 \\
Malpresentation & $12(9.1)$ & $10(3.8)$ & 3.0 & 0.08 \\
Antepartum haemorrhage & $7(9.1)$ & $8(3.0)$ & 0.08 & 0.36 \\
Postpartum haemorrhage & $9(6.8)$ & $26(9.8)$ & 0.79 & 0.37 \\
Wound infection & $2(1.5)$ & $2(0.8)$ & 0.34 & 0.56 \\
Multiple pregnancy & $3(2.3)$ & $2(0.8)$ & 1.02 & 0.31 \\
Antenatal admission & $29(22.0)$ & $13(9.9)$ & 7.25 & 0.007 \\
\hline
\end{tabular}

PIH = pregnancy induced hypertension.

Table 3. Labour outcome among the women.

\begin{tabular}{|l|c|c|c|c|}
\hline Characteristics & $\begin{array}{c}\text { Study group } \\
\mathrm{N}=132(\%)\end{array}$ & $\begin{array}{c}\text { Control group } \\
\mathrm{N}=269(\%)\end{array}$ & Chi square & P value \\
Caesarean section & $60(45.5)$ & $77(28.8)$ & 7.85 & 0.005 \\
Operative vaginal deliveries & $19(14.4)$ & $18(6.8)$ & 4.13 & 0.042 \\
Preterm delivery & $47(35.6)$ & $22(8.3)$ & 28.64 & $<0.001$ \\
Induction of labour & $26(19.7)$ & $26(9.8)$ & 5.08 & 0.024 \\
\hline
\end{tabular}

Table 4. Perinatal outcome among the women

\begin{tabular}{|l|c|c|c|c|}
\hline Characteristics & $\begin{array}{c}\text { Study group } \\
\mathrm{N}=132(\%)\end{array}$ & $\begin{array}{c}\text { Control group } \\
\mathrm{N}=132(\%)\end{array}$ & Chi square & P value \\
Still birth & $3(2.3)$ & $2(0.8)$ & 1.53 & 0.106 \\
Neonatal Death & $13(9.8)$ & $0(0.0)$ & 3.03 & 0.12 \\
BirthAsphyxia & $18(13.6)$ & $12(4.5)$ & 2.25 & 0.13 \\
Low birth weight & $3.3 \pm 0.7$ & $14(5.3)$ & 5.35 & 0.02 \\
Mean birth weight & $11(8.3)$ & $3.4 \pm 0.8$ & - & 0.43 \\
Congenital anomaly & $26(19.7)$ & $6(2.3)$ & 4.83 & 0.03 \\
Neonatal admission & & $22(8.3)$ & 7.7 & 0.007 \\
\hline
\end{tabular}

The results show that elderly women have increased risk of gestational diabetes mellitus, chronic hypertension, symptomatic fibroid and antenatal admissions for complications; this is similar to the report of others $1,2,9,10$. We did not find differences in terms of preeclampsia, obstetrics haemorrhages, malpresentation and anaemia; which Fawole et $\mathrm{al}^{3 \text {, }}$ found to have significant differences. This could be explained by the sample size which might be too small to show the difference or our matching for parity, social class and body mass index eliminated any bias. 
With regards to labour complications the older women had a higher caesarean section rate, operative delivery and preterm delivery than the young women. This could be explained by indicated intervention as a result of higher medical complications.

The perinatal mortality rate was not significantly different between the two groups. This is contrary to the documentation of a sharp rise in perinatal death in elderly women in the developed world ${ }^{2,5,10}$. However there was statistical difference in incidence of congenital anomaly, low birth weight and neonatal admission rate. The higher incidence of congenital anomaly and lower birth weight may be due to chromosome abnormality and medical complications associated with elderly women ${ }^{3,5,8,10}$.

In conclusion this study has shown that pregnancy of women aged 35 years and above women had increased risk of caesarean section, operative vaginal deliveries and higher rate of pregnancy complication than those of younger women. We therefore advocated a closer supervision during pregnancy in these women.

\section{References}

1. Kajanoja P. Widholm O. Pregnancy and delivery delivery in women aged 40 and over. Obstet Gynecol. 1978; 52(1): 4761.

2. Kirz D.S., Dorchester W., Freeman R.K. Advanced maternal age: the mature gravida. Am J Obstet Gynecol. 1985; 152: 7 - 12 .

3. Fawole A.A. Pregnancy and it's outcome among mothers 40 years and above at Ilorin, Nigeria. Nigerian Medical Practitioner. 1996; 32 (1/2): 2 - 6.

4. Gharoro E.P., Igbafe A.A. Maternal age at first birth and obstetric outcome. Tropical Journal of Obstetrics \& Gynaecology. 2002; 5(1): 20 -24.

5. Chan BCP, Lao TT. Influence of parity on the obstetric performance of mothers aged 40 years and above. Human Reproduction. 1999;14:833837.

6. Ziadeh SM. Maternal and perinatal outcome in nulliparous women aged 35 and older. Gynecol Obstet Invest. 2002; 54:6-10.

7. Salihu HM,Shumpert MN, Slay M, Kirby RS, Alexander GR. Childbearing beyond age 50 and fetal outcomes in the united states. Obstet Gynecol. 2003; 102:1006-1014.

8. Hansen J.P. Older maternal age and pregnancy outcome: A review of literature. Obstetrics and Gynaecology Survey. 1986; 41 (11): 726 - 742.
9. Nwosu U.C. Reproductive performance at 40 years and above. Tropical Journal of Obstetric and Gynaecology. 1989; 7: $11-13$.

10. Jolly M, Sebire N, Harris J, Robinson S, Regan L. The risks associated with pregnancy in women aged 35 years or older. Human reproduction. 2000;15:2433-2437.

11. Yuan W, Steffensen FH, Nielson GL, Moller M, Olsen J, Sorensen HT. Internal Journal Gynaecology Obstetrics. 2000;68: 113-118.

12. Tough SC, Newburn-Cook C, Johnson DW, Svenson LW, Rose S, Belik J. Delayed childbearing and its impact on population rate changes in lower birthweight, multiple birth, and preterm delivery. Pediatrics.2002; 109:399-403.

13. Hollander D., Breen J.L. Pregnancy in the older gravida: how old is old? Obstet Gynecol Surv. 1990; 45: $106-112$.

14. Kujansuu E., Kivinen S., Tnimala R. Pregnancy and delivery at the age of forty and over. Int. J. Obstet Gynaecol. 1981; 19: 341 - 345 .

15. Ojengbede O.A. Pregnancy and delivery at 40 years and above. Tropical Journal of Obstetrics and gynaecology.1989; 7: $11-13$.

16. Olusanya O., Okpere E., Ezimokhai M. (1985). The importance of social class in voluntary fertility control in a developing country. West African Journal of Medicine, 4, 205-212.

17. Sule-Odu A.O. Obstetrics Performance of women aged forty and over. Nigerian Medical Journal.1999; 37 (3/4): 38 - 40.

18. O'Reilly-Green C. Cohen W.R. Pregnancy in women aged 40 and older. Obstetrics and Gynaecolgy clinics of North America. 1993; 20 (2): 313-331.

19. Loto OM, Ezechi OC, Kalu BKE, Loto AB, Ezechi LO, Ogunniyi SO. Poor obstetric performance of teenagers: is it age or quality of care related? Journal of Obstetrics \& Gynaecology. 2004; 24:397-400.

20. Kirchengast S, Hartmann B. Impact of maternal age and maternal somatic characteristics on newborn size. American Journal of Human Biology. 2003;15:220-228.

21. Gilbert WM, Nesbitt TS, Danielson B. Childbearing beyond age 40: pregnancy outcome in 24032 cases. Obstetrics \& Gynaecology. 1999:93:9-14. 